Public Health

\section{Resurgence of early congenital syphilis}

\section{in Alberta}

I n Alberta, the first case of congenital syphilis in over to years was reported in 2002. This was after a resurgence in the province in 2000 of locally acquired infectious syphilis, in many cases affecting people who reported casual or anonymous sexual partnering.

In I996, Canada set a goal to maintain the rate of infectious syphilis at no more than 0.5 per 100000 population. ${ }^{1}$ At that time, the elimination of syphilis in Canada seemed achievable. ${ }^{2}$

However, the following year (midn 1997), an outbreak of infectious syphi趸 lis was reported in downtown Vancouver. ${ }^{3}$ Between 1996 and 2006, Alberta experienced a progressive rise in cases of infectious syphilis, from o in 1996 to 6.5 per 100 ooo in 2006. In the northern part of the province, this outbreak has involved mostly heterosexual people, but in the south, it affects mainly men who have sex with men.

Syphilis serology is routinely performed for all pregnant women who obtain antenatal care in Alberta. In 2006,50 of 55723 prenatal tests were reactive by rapid plasma reagin, with $\mathrm{I} 2$ confirmed infectious and 18 confirmed noninfectious cases after individual case review (20 cases were previously treated or false positive). During 2005 and 2006, a total of 9 babies were born in Alberta with congenital syphilis; the neonatal and maternal characteristics in these cases are outlined in Table I and Table 2. Six of the 9 mothers were First Nations women. None of them were coinfected with HIV at the time of diagnosis; preliminary reports indicate that in the rest of Canada, there were 3 cases in 2005 and 4 cases in 2006. ${ }^{4}$

In 4 of the 9 Alberta cases of congenital syphilis, the mother did not obtain antenatal care before the onset of labour. In I case, the mother tested positive for syphilis but could not be located for several weeks.

Table 1: Characteristics of 9 mothers in Alberta who each delivered a baby (in 2005 or 2006) with early congenital syphilis

\begin{tabular}{lccccccc}
\hline Residence & No. & $\begin{array}{c}\text { Marital } \\
\text { status* }^{*}\end{array}$ & $\begin{array}{c}\text { Age } \\
\text { group }\end{array}$ & $\begin{array}{c}\text { Sex } \\
\text { trade } \\
\text { worker }\end{array}$ & $\begin{array}{c}\text { Syphilis } \\
\text { test before } \\
\text { delivery }\end{array}$ & $\begin{array}{c}\text { Stage of } \\
\text { maternal } \\
\text { syphilis }\end{array}$ & $\begin{array}{c}\text { Treated } \\
\text { during } \\
\text { pregnancy }\end{array}$ \\
\hline Edmonton & 8 & $\begin{array}{l}5 \text { partnered } \\
3 \text { unpartnered }\end{array}$ & $15-40$ & 5 of 8 & $\begin{array}{c}4 \text { yes } \\
4 \text { no }\end{array}$ & $\begin{array}{c}5 \text { primary } \\
3 \text { secondary }\end{array}$ & $\begin{array}{c}7 \text { no } \\
1 \text { yes }\end{array}$ \\
Nonurban & 1 & Partnered & $30-35$ & No & Yes & Primary & No \\
\hline
\end{tabular}

*Partnered = married or cohabiting (common-law), unpartnered = single or separated.

†Mother tested positive for syphilis 2 months before delivery but could not be located for treatment until the day of delivery.

Table 2: Fetal or neonatal characteristics of 9 babies with early congenital syphilis

\begin{tabular}{lccc}
\hline $\begin{array}{l}\text { Gestational age } \\
\text { at delivery, wk }\end{array}$ & $\begin{array}{c}\text { Age at start } \\
\text { of treatment, } \\
\text { range, d }\end{array}$ & \multicolumn{1}{c}{ Characteristics of each baby } \\
\hline 26 & 1 & No treatment & Died within hours of birth, hepatosplenomegaly \\
$<37$, preterm & 4 & $0-13$ & $\begin{array}{l}\text { Abnormal CSF, microcephaly at 6 mo } \\
\text { Hepatosplenomegaly, hydrops fetalis, abnormal CSF } \\
\text { Blind, long-bone abnormality, abnormal CSF } \\
\text { Hydrops fetalis, abnormal CSF }\end{array}$ \\
At term & 4 & $0-248$ & $\begin{array}{l}\text { Abnormal CSF } \\
\text { Hepatosplenomegaly, anemia } \\
\text { Hepatosplenomegaly, desquamating rash, anemia } \\
\text { Hepatosplenomegaly, desquamating rash, anemia }\end{array}$ \\
\hline
\end{tabular}

Note: CSF = cerebrospinal fluid.

In the remaining 4 cases, the mothers tested negative earlier in the pregnancy but acquired the infection later. Although 2 of these mothers had the classic genital ulcers of primary syphilis within I month before delivery, syphilis had not initially been considered as the cause. One mother had begun antiviral therapy for an incorrect diagnosis of genital herpes and underwent an elective cesarean section.

One baby, born late in 2006, was brought to hospital at 3 months of age with severe desquamating skin rash, massive hepatosplenomegaly, hyponatremia and anemia. Earlier in the pregnancy, the mother's syphilis serology had been reported as nonreactive; she had been married for 15 years. Her secondary syphilis was diagnosed subsequent to confirmation of the infant's infection. For this baby and for the most recently treated baby (whose diagnosis was made at 8 months of age), the initial diagnosis was juvenile myelomonocytic leukemia, on the basis of their presentation with hepatosplenomegaly, desquamating rash and anemia.

The Canadian Guidelines on Sexually Transmitted Infections ${ }^{4}$ currently recommend repeat testing for syphilis for women who remain at high risk for this disease during pregnancy (Box I). The syphilis chapter of the guidelines will soon be revised to include, in addition to the criteria given in Box I, recommendations for rescreening women who reside in areas where syphilis outbreaks are affecting heterosexual people. Of note, the diagnosis of congenital syphilis in the 2 babies described in the preceding paragraph was delayed because their mothers did not meet criteria for rescreening for syphilis during pregnancy, since their husbands' extramarital activities were unknown at the time of delivery.

\section{Risk of transmission from mother to child}

Transmission of syphilis to a fetus depends largely on the duration of the disease in the mother. ${ }^{5}$ The longer the interval between infection and pregnancy, the more benign the outcome in the in- 


\section{Box 1: Risk factors for syphilis*}

In addition to patients with signs or symptoms compatible with syphilis, the disease should be considered in the differential diagnosis of:

- Those who have had contact (sexual or perinatal) with someone known to be infected with syphilis

- Men who have sex with men

- Sex trade workers

- Those with street involvement or who are homeless

- Users of injection drugs

- People who have multiple sexual partners

- Those with a history of syphilis, HIV and other sexually transmitted infections

- People from or having sex with someone from a country with a high prevalence of syphilis (note that all applicants for immigration to Canada who are 15 years or older are routinely screened for syphilis, with a nontreponemal test)

- Sexual partners of any of the above

*Source: ${ }^{4}$ Canadian Guidelines on Sexually Transmitted Infections 2006 edition, Public Health Agency of Canada, 2006. @ Adapted and reproduced with the permission of the Minister of Public Works and Government Services Canada, 2007.

fant (Kassowitz's law). ${ }^{6}$ The risk of transmission is $70 \%-100 \%$ in women with primary or secondary syphilis, $40 \%$ with early latent syphilis and $10 \%$ in late latent cases. ${ }^{7}$ About $40 \%$ of pregnancies in women with infectious syphilis result in the death of the fetus. ${ }^{8}$ Spirochetes can cross the placenta and infect the fetus at as early as 9 weeks of gestation, with the risk of fetal infection increasing with gestational age. ${ }^{9}$ The clinical spectrum in surviving infants ranges from a complete lack of symptoms to severe clinical manifestations.

\section{Screening and rescreening of pregnant women and newborns}

Routine screening during pregnancy for syphilis remains the standard of care for women in Canada. Box I lists the criteria for everyone at risk for syphilis. Pregnant women with these characteristics and those from geographic areas with an outbreak of infectious syphilis should be rescreened for syphilis at 28-32 weeks and again at the time of delivery. In addition to these criteria, Aboriginal women should be rescreened in geographic areas experiencing outbreaks affecting Aboriginal communities.

Women newly infected with syphilis may not be aware of symptoms, particularly if their ulcers are painless and on the internal genital tract.
All women testing positive for syphilis should also be screened for HIV; coinfection with HIV affects immediate medical management and the duration of follow-up. Because people infected with syphilis are at increased risk of HIV infection, and in light of the window period (tests for HIV antibodies tend not to show positivity until at least 4 weeks after transmission), HIV serology should also be repeated later in pregnancy. Other sexually transmitted infections (e.g., gonorrhea, chlamydia) should be tested for in all cases, with screening tests for hepatitis B and C as indicated. All genital ulcers should be tested for herpes simplex virus as well. Criteria for screening and evaluation for neonatal or early congenital syphilis are listed in Box 2. No infant should leave a hospital without the mother having been tested for syphilis at least once during pregnancy.

\section{Management}

Mothers diagnosed with infectious syphilis should be treated with the appropriate dose of benzathine penicillin $\mathrm{G}$ according to their stage of syphilis infection and the presence or absence of HIV coinfection. Despite the administration of a single-dose penicillin regimen, as many as $14 \%$ of women with secondary syphilis in late pregnancy will undergo a fetal death or deliver infants with clinical evidence of congeni-
Box 2: When to evaluate or screen* for neonatal or early congenital syphilis infection

- Stillborn infants with a gestational age of 20 weeks or more

- Asymptomatic infants born to mothers who were, during pregnancy:

- Not tested for syphilis

- At continued high risk for infection after a negative test result earlier in the pregnancy $†$

- Infants with any of these signs:

- Snuffles or nasal dischargef

- Hepatosplenomegaly

- Distended abdomen

- Desquamative skin rash

- Infants found (via blood testing) to have hemolytic anemia

- Infants with compatible abnormalities of the long bones (shown by radiography)

*Screening tests can be done on the mother or infant, depending on the clinical situation. †See Box 1 for risk factors.

$\ddagger$ The earliest sign; occurs $1-2$ weeks before the onset of rash.

tal syphilis. ${ }^{10-12}$ Some specialists recommend that any pregnant woman with infectious syphilis receive 2 doses of 2.4 million units of benzathine penicillin G, administered I week apart, although the efficacy of this regimen in preventing fetal syphilis is as yet unknown. ${ }^{13,14}$ It is also essential that all sexual partners be tested and treated for syphilis concurrently, to prevent reinfection of the mother.

At the present time, benzathine penicillin $\mathrm{G}$ is not manufactured in Canada and is available only through provincial or territorial sexually transmitted disease services, who obtain the drug through Health Canada's Special Access Programme. This long-acting preparation achieves detectable serum levels of penicillin for 2-4 weeks in nonpregnant adults, and is required for treatment of infectious syphilis to be successful; short-acting penicillin agents are inadequate to achieve a cure. ${ }^{15}$

There is no satisfactory alternative to penicillin for the treatment of syphilis during pregnancy. Data on the use of ceftriaxone are not yet sufficient; erythromycin does not penetrate the placental 
barrier well. ${ }^{16,17}$ Women with a history of allergy to penicillin should be desensitized and then treated with penicillin. ${ }^{18}$ A Jarisch-Herxheimer reaction (in response to the rapid death of infectious organisms) during the first 24 hours after treatment may precipitate premature labour or fetal distress; any pregnant woman being treated should be advised to seek immediate medical attention if she experiences contractions or perceives reduced fetal movement.

In the second half of pregnancy ( $\geq 20$ weeks), women with syphilis should be managed with detailed ultrasonographic assessments in conjunction with a maternal-fetal medicine specialist. If abnormalities such as hepatomegaly, ascites, hydrops or placental thickening are present, the mother should be admitted for treatment and observation..$^{19}$ The ultrasound should be used as a tool to "stage" the extent of fetal disease during the second half of pregnancy.

Close follow-up of mother and fetus is necessary after treatment, with serologic testing appropriate to the stage of infection. In women at high risk for reinfection, monthly syphilis testing may be indicated.

When infants born to mothers with infectious syphilis are evaluated, a venous sample should be obtained from both mother and baby (cord blood is unsuitable) for treponemal and nontreponemal serology. The interpretation of a neonate's reactive antibodies must take maternal history into consideration, including her stage of syphilis, treatment history and syphilis serology
In spite of treatment the most prolonged, the most strictly followed, and the best suited to the nature of the symptoms, it is never perfectly certain that they will not return. Consequently, we can never have the positive assurance that the germ of syphilis is altogether extinct, that it will not reveal its survival by the birth of a contaminated child. — Paul Diday, A Treatise on Syphilis in Newborn Children and Infants at the Breast. London; 1859 . results. Samples of placenta, neonatal nasal discharge or skin lesions should be examined by dark-field microscopy, direct or indirect immunofluorescence assay, or polymerase chain reaction for Treponema pallidum. In addition, all infants with suspected congenital syphilis should undergo lumbar puncture for cerebrospinal fluid and long-bone radiography. Ideally, all such infants should be managed by or in conjunction with a pediatric infectious diseases specialist.

Infants should be treated at birth with crystalline penicillin $\mathrm{G}$ for Io days if (I) they are symptomatic; (2) their rapid plasma reagin result is fourfold ( 2 tubes) as high as the mother's; (3) maternal treatment was inadequate, did not contain penicillin, is unknown or occurred during the last month of pregnancy; or (4) the maternal serologic response is inadequate and/or adequate follow-up of the infant cannot be ensured. Some experts recommend that a single intramuscular dose of 50000 units/kg of benzathine penicillin $\mathrm{G}$ be given to infants born to mothers with infectious syphilis who can be confirmed to have had adequate treatment; where there is no concern about maternal reinfection; and when clinical and laboratory examination in the in-

\section{Key messages}

- Rates of congenital syphilis have risen in Canada after outbreaks of infectious syphilis in some locales.

- Routine screening for syphilis remains the standard of care for all pregnant women; those at high risk for syphilis should be rescreened later in pregnancy or at delivery.

- Pregnant women with infectious syphilis should be treated with benzathine penicillin $\mathrm{G}$ at a dosage appropriate for the mother's stage of infection; sexual partners should be located and also treated.

- Pregnant women with infectious syphilis, particularly after 20 weeks of gestation, should be managed in conjunction with a maternal-fetal specialist and with ultrasound evaluations.

- Infants born to mothers who have infectious syphilis should be assessed by or in conjunction with a specialist pediatrician; those who require treatment should be treated with crystalline penicillin $\mathrm{G}$ administered intravenously, and intense clinical and serologic follow-up should be provided. fant are normal. ${ }^{14}$ However, there are few data to support this approach.

Follow-up serologic testing of newborns should be performed at regular intervals. ${ }^{20}$ If the infant was not infected, rapid plasma reagin titres should decline by 3 months of age and be nonreactive by 6 months. If a child's titres are stable or increase after 6I2 months of age, he or she should be evaluated (including CSF examination) and treated for congenital syphilis. Treponemal antibodies passively transferred from the mother can be present in an infant for as long as 15 months; a reactive treponemal antibody test after I8 months of age is diagnostic for congenital syphilis.

\section{Conclusions}

Given the resurgence of congenital syphilis in Alberta, continued screening of all pregnant women for syphilis is vital. It is important to rescreen high-risk mothers and those living in areas experiencing heterosexual outbreaks of syphilis at 28-32 weeks' pregnancy and again at delivery. All infected mothers should be treated with appropriate penicillin regimens and managed in conjunction with a specialist in maternal-fetal medicine. Clinicians should have a high index of suspicion for congenital syphilis and screen neonates presenting with signs compatible with congenital syphiselect circumstances. All infants born to mothers with infectious syphilis should receive intensive clinical and laboratory follow-up in conjunction with a pediatric specialist.

To further limit the devastating consequences of congenital syphilis, additional research and enhancement of public health capacity are necessary to develop strategies for the primary prevention of syphilis, improvements in access to prenatal care by high-risk and vulnerable populations, and assessment of sexual partners' risk factors for lis, as well as asymptomatic infants in 
syphilis. Finally, it will be important to raise public and provider awareness of the resurgence of this ancient disease. Appropriate strategies to achieve this goal include communication efforts (such as mass mailings) to alert clinicians to the resurgence of syphilis and to encourage increased screening of those at risk. Other strategies might include heightening media awareness by way of press releases; disseminating information through newspaper, radio and television announcements; and involving key stakeholders (including government, communities, and involved or at-risk populations) in both increasing awareness and undertaking prevention strategies.

\section{Ameeta Eshri Singh BMBS MSc}

Alberta Health and Wellness and Capital Health STD Centre University of Alberta

Karen Sutherland RN BScN

Alberta Health and Wellness

Bonita Lee MD MSc

Joan Louise Robinson MD

University of Alberta

Alberta Provincial Laboratory for

Public Health

Edmonton, Alta.
Tom Wong MD MPH

Public Health Agency of Canada

Ottawa, Ont.

This article has been peer reviewed.

Competing interests: None declared.

Consent to publish non-nominal information about the cases in this article was provided by Dr. K. Grimsrud, Acting Chief Medical Officer of Health, Alberta Health and Wellness.

Acknowledgements: We are indebted to the staff of the Capital Health STD Centre, Alberta Health and Wellness STD Services and Provincial Laboratory for Public Health for the provision of data and outstanding clinical care.

\section{REFERENCES}

I. Health Canada. Proceedings of the national STD consensus meeting. Can Commun Dis Rep I997; 23(S6):2-9.

2. Wong T, Jordan R. Syphilis elimination in Canada: If not now, when? Can J Hum Sex 2000;9:205-9.

3. Rekart M, Patrick D, Jolly A, et al. Mass treatment/ prophylaxis during an outbreak of infectious syphilis in Vancouver, British Columbia. Can Commun Dis Rep 2000;26:10I-5.

4. Public Health Agency of Canada. Canadian guidelines on sexually transmitted infections. 2006 edition. Ottawa: Her Majesty the Queen in Right of Canada; 2006. Available: www.phac-aspc.gc.ca/std -mts/sti_2006/pdf/sti2006_e.pdf (accessed 2007 May 8).

5. Wicher V, Wicher K. Pathogenesis of maternal-fetal syphilis revisited. Clin Infect Dis 2001;33:354-63.

6. Evans HE, Frenkel LD. Congenital syphilis. Clin Perinatol I994;2I:I49-55.
7. Sanchez PJ, Wendel GD, Grimpel E, et al. Evaluation of molecular methodologies and rabbit infectivity testing for the diagnosis of congenital syphilis and central nervous system invasion by $T$. pallidum. JInfect Dis 1993;167:148-57.

8. Finelli L, Berman SM, Koumans EH, et al. Congenital syphilis. Bull World Health Organ I998;76 (Suppl 2):126-8

9. Harter C. Benirschke K. Fetal syphilis in the first trimester. Am J Obstet Gynecol I976;124:705-II.

Io. McFarlin B, Bottoms SF, Dock BS, et al. Epidemic syphilis: maternal factors associated with congenital infection. Am J Obstet Gynecol I994;170:535-40.

II. Mascola L, Pelosi R, Alexander CE. Inadequate treatment of syphilis in pregnancy. Am J Obstet Gynecol I984;150:945-7.

I2. Conover CS, Rend CA, Miller GB Jr, et al. Congenital syphilis after treatment of maternal syphilis with a penicillin regimen exceeding CDC guidelines. Infect Dis Obstet Gynecol I998;6:134-7.

13. Genc M, Ledger WJ. Syphilis in pregnancy. Sex Transm Infect 2000;76:73-9.

I4. Centers for Disease Control and Prevention. Sexually transmitted disease guidelines, 2006. $M M W R$ Morb Mortal Wkly Rep 2006;55(RR-II).

I5. Peter G, Dudley MN. Clinical pharmacaology of benzathine penicillin. Pediatr Infect Dis 1985;4: 586-9r.

I6. Kiefer L, Rubin A, McCoy JB, et al. The placental transfer of erythromycin. Am J Obstet Gynecol I955;69:174-7.

I7. Philipson A, Sabath LD, Charles D. Transplacental passage of erythromycin and clindamycin. $\mathrm{N} \mathrm{EnglJ}$ Med I973;288:I219-2I.

I8. Wendel GD Jr, Stark RJ, Jamison RB, et al. Penicillin allergy and desensitization in serious infections during pregnancy. $N$ Engl J Med I985;312: I229-32.

I9. Wendel GD Jr, Sheffield JS, Hollier LM, et al. Treatment of syphilis in pregnancy and prevention of congenital syphilis. Clin Infect Dis 2002;35(suppl 2):S200-9.

20. Sanchez PJ, Wendel GD. Syphilis in pregnancy. Clin Perinatol I997;24:7I-90.

\section{Numéro des Fêtes de 2007 Appel de documents}

L'hilarité et la bonne humeur (...) aident énormément à la fois dans l'étude et dans la pratique de la médecine. (...) Être de mauvaise humeur quand on se présente devant les patients, voilà un péché impardonnable.

- William Osler

Du bizarre au litigieux, en passant par le simplement divertissant — nous voulons de tout! En effet, le moment est venu de nous faire parvenir vos créations littéraires pour le numéro des Fêtes 2007 du JAMC. Nous recherchons les textes humoristiques, parodies, réflexions personnelles, histoires de la médecine et explorations scientifiques hors de l'ordinaire.

Veuillez nous faire parvenir vos textes par notre système d'envoi de manuscrits en ligne (http://mc.manuscriptcentral.com/jamc). Les articles ne doivent pas dépasser 1200 mots et les photographies et illustrations sont les bienvenues. Veuillez indiquer dans votre lettre d'accompagnement que vous soumettez votre texte pour le numéro des Fêtes de cette année.

$$
\text { Les textes doivent nous parvenir au plus tard le }{ }_{1}^{\text {er }} \text { octobre } 2007 .
$$

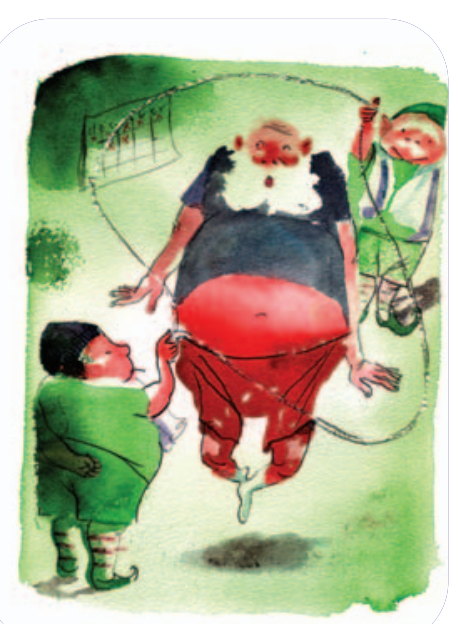

